\title{
Working with Memory in the Archaeology of Modern Conflict
}

\author{
Gabriel Moshenska
}

\begin{abstract}
The aim of this article is to situate archaeological approaches to modern conflicts within a framework of conflict memory and commemoration. A critical appreciation of historical archaeology as a commemorative practice requires a firm grounding in memory theory, specifically the formation and contestation of memory narratives. This article offers a detailed analysis of the relevant theories and demonstrates their applicability in the contested archaeology of the Nazi era in Berlin. On the basis of this critique I argue that archaeological work on contested sites offers a unique and powerful forum for socially engaged interdisciplinary research.
\end{abstract}

The development of archaeological approaches to the study of twentieth-century conflicts is a challenging and exciting element of contemporary historical archaeology (McAtackney \& Palus 2007; Saitta 2007; Schofield \& Cocroft 2007). Many scholars working in this field have noted the value of memory as a concept encompassing war memorials, souvenirs, oral history interviews and commemorative rituals (e.g. Saunders 2004; Schofield 2005; Tarlow 1999). There is also a growing awareness that archaeological work on sites of conflict can have a mnemonic or commemorative function in itself, with commensurate benefits, risks, practicalities and ethical problems (Fraser \& Brown 2007; Moshenska 2008; Price 2004). The social and political impact of an archaeological intervention can come as a surprise: Beck et al. $(2009,103)$ anticipated some of the problems involved in studying a protest camp in Nevada, but admit that 'we were not prepared for our research to create its own political milieu'.

One of the deficiencies of modern conflict archaeology as it stands is the paucity of critically engaged studies of memory. There are a very small number of studies that use oral history in a serious and organized fashion (Rodgers et al. 1998; Schofield et al. 2001) as well as a growing number of anthropological perspectives on war memorials in all their forms (Black 2004). The idea that conflict memory is contested, often violently, is beginning to emerge in modern conflict archaeology, as researchers move into fields such as Spain and
South America where narratives of past conflicts are particularly sensitive political issues (Crossland 2000; 2002; González-Ruibal 2007). There is space and a clear need for a more comprehensive model for memory in modern conflict archaeology, drawing out the connections and underlying power relations between individual memory, small group memory narratives, hegemonic memorialization processes, and the plethora of performances, sites and cultural processes through which they are contested and negotiated.

In this article I attempt to create a framework for memory work in contemporary archaeology based on a critique of memory theory, focusing in particular on memory dynamics and power on and around contested sites. The article has three sections: the first introduces the field of memory studies in general and focuses on the relationship between individual and collective memory, examining historical perspectives as well as considering the role of agency and intersubjectivity in formulating memory narratives. The core of the second section is a critical assessment of a framework for conflict-memory analysis, focusing on the public articulation of memory narratives. Within this model narratives are formed collectively by small groups who use arenas of memory articulation such as commemorative events to raise popular awareness of their narratives, while agencies of memory articulation are groups that use their power and influence to promote, challenge or suppress different memory 
narratives. The third section of the article integrates archaeological practices into this framework of memory articulation and analysis. This section focuses on the idea that archaeological sites can function as arenas for memory articulation, and explores the validity of this theory as well as its implications and possibilities. This final section includes a case study of an archaeological site of contested conflict memory in Germany: the Active Museum's Let's Dig! excavations in West Berlin in 1985, and examines the applicability and utility of the ideas and models outlined in this article.

\section{The emergence and development of memory studies}

The development of memory studies from the end of the nineteenth century to the present reflects many of the central events of the twentieth century. Memory studies is by no means a unified, coherent field: straddling the arts, humanities and social sciences as well as aspects of medicine and the biological sciences it remains 'a nonparadigmatic, transdisciplinary, centerless enterprise' (Olick \& Robbins 1998, 106). Numerous theories have been put forward to explain the recent rise in academic memory studies, including the possibility that memory is a largely meaningless term increasingly co-opted as socio-political capital (Gedi \& Elam 1996). More than one scholar has suggested that the much-trumpeted interdisciplinarity of memory studies elides a decline in specialisms where the memory franchise has taken hold:

For years, specialists have dealt with such wellknown phenomena as oral history, autobiography, and commemorative rituals without ever pasting them together into something called memory. Where we once spoke of folk history or popular history or oral history or public history or even myth we now employ memory as a metahistorical category that subsumes all these various terms. (Klein 2000, 128)

The increasing prominence of memory in these fields has been ascribed to the emergence of post-colonialism; the crises of modernity and post-modernity; the decline of 'actual' memory; the decline of historicism; a response to the traumas of two World Wars and the Holocaust; and the emergence of identity politics (Klein 2000, 143; Radstone 2000; Wood 1999). None of these adequately explain the full complexity of the memory discourse nor do they offer solutions to the many conflicts within memory studies outlined in this article. While my focus is on those aspects that relate to the memory and commemoration of conflict it is worth locating this work within the developmental narratives of the most influential mnemonic discourses.
The origins of memory studies

The relationship between the personal memory of individuals and the various conceptions of collective memory is complicated; a critical and analytical approach to memory must first unpick the tangle of extraneous terminology and woolly thinking that surrounds it. This section traces the development of the idea of collective memory in oral history, history and memory studies, focusing particularly on ideas of memory as an active, performative process. The result is an agent-centred view of memory in society, emphasizing the importance of individuals and small groups in the creation and propagation of memory narratives. This model plays an important role in subsequent discussions of memory communities and the power of memory.

The shift in memory studies that followed the First World War, characterized by the emergence of public commemorative practices, physical memorials and a heightened understanding of trauma, was largely based on works published a generation earlier. Winter argued that 'the memory boom of the late twentieth century arrived in part because of our belated but real acceptance that among us, within our families, there are men and women overwhelmed by traumatic recollection' (Winter 2000, 79). Foundational texts by Bergson and Freud developed theories of memory and the mind that influenced the writings of Proust, Joyce and Woolf amongst others, along with the development of psychological theories of shell-shock, trauma and 'war neuroses' in the works of Freud and W.H.R. Rivers (Bergson 1988; Radstone 2000, 16; Winter 2006, 20).

In the interwar period some of the most important foundational work on memory and society was carried out in a remarkably short period of time by a number of scholars in disparate fields including the psychologist Frederic Bartlett, the historian Marc Bloch, the art historian Aby Warburg and the cultural theorist Walter Benjamin, as well as a number of hugely influential books by the sociologist Maurice Halbwachs, discussed below (Assman 1995, 125; Confino 1997, 1390; Olick \& Robbins 1998, 106). The key development in all of this work was the idea that memory narratives were to some extent constructed in relation to social or cultural forces; this set out a framework for memory work in the humanities and social sciences, as well as challenging the popular and pernicious nineteenth-century notion of inheritable race-memory (Assman 1995).

Maurice Halbwachs is the godfather of contemporary memory studies; his works on the 'social frameworks of memory' have been described as 'the 
theoretical anchor for all memoriologists' (Gedi \& Elam 1996, 35). Halbwachs reacted against the individualism of early twentieth-century psychology to formulate a theory of collective memory that subordinated the individual to the collective, to the extent that the individual is almost entirely irrelevant. He argued that our memories are formed through dialogue within social groups, and as such the memory of the greatest number or the most powerful subgroup becomes the official memory of the collective (Green 2004; Wood 1999). Critics of Halbwachs have claimed that this leads to

a concept curiously disconnected from the actual thought processes of any particular person. Thus, an important problem facing anyone who wants to follow Halbwachs in this field is how to elaborate a conception of memory which, while doing full justice to the collective side of one's conscious life, does not render the individual a sort of automaton, passively obeying the interiorised collective will. (Fentress \& Wickham 1992, ix)

Halbwachs himself claimed that the idea of an individual memory, absolutely separate from social memory, is an abstraction almost devoid of meaning' (in Kansteiner 2002, 185). However, Halbwachs' view of the individual is not as crudely functionalist as it might appear: the role of the collective is more strongly associated with the actual, active recall of memories; the individual is subordinate but by no means absent (Green 2004, 38; Halbwachs 1992).

\section{Forms of collective memory}

Collective memory is a term commonly used to refer to memory on a super-individual level (see Halbwachs 1992; Nora 1989), along with a variety of others including 'social memory' (Connerton 1989; Fentress \& Wickham 1992) and 'cultural memory' (Hodgkin \& Radstone 2003; Huyssen 1995). The tensions and misunderstandings within and around these terms, often based on lack of clarification or mistranslation, are increasingly leading to criticism:

Collective memory as a term is widely considered unsatisfactory, especially by anthropologists and oral historians; it fosters generalizations and describes a reality which does not in fact exist. (Cappelletto 2005, 9)

The idea that memory can exist outside of the minds of individuals is of course a contentious issue, but one that scholars of memory have tended to gloss over or sidestep. Some have suggested that what is needed are new broader conceptions of what memory actually signifies, drawing on the works of Nora, Samuel and others (Hodgkin \& Radstone 2005, 130; Radstone 2005; Samuel 1994). The historian Joanna Bourke takes a less indulgent view:
As Marc Bloch warned, it is never wise to borrow a term from psychology and preface it with the word 'collective'. Amongst the dangers in using the metaphor of 'memory' to refer to commemorative sites or shared narratives of the past is the fact that it threatens to elide problems of causality. After all, individuals 'remember', 'repress', 'forget' and 'are traumatized', not societies. (Bourke 2004, 473)

Perhaps the most interesting themes to trace through the critical analyses of different conceptions of collective memory are these very different ideas of the 'collective', and the sometimes utterly divergent understandings of 'memory'. This highlights the need not only to chart these differences but to forge a clear understanding of which meanings can be regarded as analytically sound concepts producing valid, usable results. One would hope that the interdependence of individual and collective memory could be taken for granted in all contemporary analyses of memory, leaving the precise nature of the relationship open to discussion. As Kansteiner has observed:

Recent psychological and neurological studies give ample reason for the conflation of individual and collective memory because such research has time and again emphasized the social nature of individual remembering and forgetting. Even on a neurological level our ability to store, recall and reconfigure verbal and nonverbal experiences and information cannot be separated from patterns of perception which we have learned from our immediate and wider social environments. (Kansteiner 2002, 185)

The rise of collective-memory studies and its convergence with oral history has led to a widespread fascination with the social construction of memory narratives to the exclusion of the individual, who is "either subsumed under "collective memory", or assigned to the realm of the passive unconscious' (Green 2004, 36); 'in the case of oral history, it is now widely accepted that personal accounts of the past do not necessarily offer direct access to that past (Radstone 2005, 135).

From this perspective it is the media, popular culture and other environmental factors that reshape individual memories though the creation of powerful and influential cultural scripts into which personal experiences are woven to create memory narratives (Popular Memory Group 1982). This exposition of the relations of production of memory is a powerful component in our understanding of hegemonic memory:

Central to this work is the distinction between 'public representations' and 'private memory'. The former term refers to those representations of the past that 'achieve centrality' within the public domain, where their institutional propagation by the national and 
local state, the culture industries or the public media ensure their scope to make public meanings for vast audiences. Private memory, by contrast, refers to the 'more privatised sense of the past' which circulates among particular social groups in the course of everyday life'. The interaction between these aspects of memory is understood in Gramscian terms, as a hegemonic process of ideological domination and resistance. (Ashplant et al. 2000, 13)

As we can see, even in this radical formulation of memory the role of the individual has been eclipsed by the notion of discourse within social groups.

\section{Agency and intersubjectivity}

How might we move beyond this cultural determinist view of collective memory to an understanding of the role of the individual? To begin we must recognize that Halbwachs' model of the individual as a passive automaton is unsound, while the idea that memory can exist at a purely individual level unmediated by cultural influences is equally untenable. Lastly the focus on collective memory at a national level or other more abstract scales is problematic; a more realistic level of collectivity might lead to better results. If, as Green suggests, 'the three strands of contemporary life narrative and oral history interpretive theory - the cultural, social and psychoanalytic - all lean towards a culturally determinist and functionalist perspective concerning individual memory' $(2004,40)$, then some course correction is necessary if any meaningful results are to be obtained.

Memory narratives created by individuals and groups reflect not only their social milieu but also their personal and collective strategies, often in opposition to the national or other collective memory. A 'third way' is required, bridging these two extremes and taking into account the role of individual agents (Edkins 2003, 33). The clearest and most influential attempt to chart this third way comes from Winter \& Sivan in their study of war memory. They reject the notion of collective memory in favour of 'collective remembrance', the 'activity of individuals coming together in public to recall the past' $(1999,11)$ :

the key mid-point ... between homo psychologicus - the man of private memory - and homo sociologicus - the man of socially determined memory - is action. Homo actans is our subject. He or she acts, not all the time, and not usually through instruction from on high, but as a participant in a social group constructed for the purposes of commemoration ... we stand at a mid-point between two extreme and unacceptable positions in this field: between those who argue that private memories are ineffable and individual, and those who see them as entirely socially determined, and therefore present whether of not anyone acts on them. With Blondel, we urge that such approaches are best located in 'the gallery of useless abstractions'. In between is the palpable, messy activity which produces collective remembrance. In this as in other areas, agency is arduous. (Winter \& Sivan 1999, 10)

Activity in this middle ground between the individual and collective has been characterized as intersubjective; focusing on the interaction of individuals at small-scale community level. Reflecting on the use of psychoanalytical terminology in memory studies, Papoulias suggests that at the level of collective memory the intersubjective relation plays the part of the Freudian unconscious in the individual, shaping and reworking memories (2003, 118). Cappelletto's analysis of war memory in small-scale communities suggests the term 'group memory' rather than collective, as this better describes the intersubjective nature of the writing of memory narratives $(2005,10)$.

In shifting the focus of the commemoration of war away from the collective and towards the individual agent, Winter \& Sivan's work downplayed the role of politics and the state in forming memories of conflict. This has been criticized by Ashplant et al. $(2000,9)$ both for its overly vague formulations of memory communities 'in the borderlands linking families, civil society and the state' and more generally for its over-simplistic distinctions between political and psychological processes of bereavement and commemoration.

Following Winter \& Sivan's general idea of the individual actor, Green argues that it is the concept of agency in its broadest sense that can bring the individual back into the centre of memory studies, once we recognize 'the capacity of the conscious self to contest and critique cultural scripts or discourses $\ldots$ and explore those points of conflict and rupture in people's lives that create confrontations with discourses of power' $(2004,42-3)$. It is the focus on this conflict that makes war memory such a rich seam for students of memory to mine, and the strength of an archaeological approach, as I will argue, lies in its ability to renegotiate the status of sites and objects of memory.

\section{Memory dynamics in the real world}

From the discussion above we have established that memory as a subject of study is best understood as a process of active remembrance. Individual and group agency have been identified as the sources of collective remembrance, acting through what Winter \& Sivan 
refer to as 'social group[s] constructed for the purposes of commemoration' $(1999,10)$. To carry out critical and reflexive interventions into memory we need a clearer understanding of these memory communities and the mechanisms and frameworks within which they operate. In this section I examine and compare various conceptions of mnemonic communities from a number of recent studies in history and anthropology, focusing on the points of agreement and divergence hidden behind the different terminologies.

Following this, I consider the unique features of war or conflict memory, particularly in the creation of fragmented and polarized memory communities within geographically defined groups. This inevitably involves a discussion of individual trauma, as well as social tension. Finally, I examine the potential of these tensions within and between memory communities to contribute to what Sulieman has called 'crises of memory' $(2006,1)$, in which discourses of memory burst violently into the public sphere. Highlighting these cases and their tendency to crystallize around significant sites or material culture leads into my third section in which I consider the impact of archaeology on these processes.

To set the framework for this section, I will first examine the elaborate model of the mechanisms for the public articulation of memory proposed by Ashplant and colleagues (2000, 16); its development and criticism of earlier conceptions and its potential uses in creating an archaeological model of conflict memory work.

The politics of war memory and commemoration is precisely the struggle of different groups to give public articulation to, and hence gain recognition for, certain memories and the narratives within which they are structured. (Ashplant et al. 2000, 16)

The idea of memory as a publicly situated process is central to my project, and the concept of memory articulation lies at the very core of this. Countless memory conflicts have revolved around the issue of representation: whose memories are pushed to the fore and whose are suppressed or fragmented. Ashplant et al. identify three consistent elements within these struggles: narratives, arenas and agencies of memory articulation (2000, 16-17). These categories and their implications are considered in more depth below.

\section{Narratives of articulation}

Narratives of memory articulation are the result of the processes discussed in the first section of this article: the product of collective or group remembrance, the forms in which memories are projected onto the national or larger-group discourse. These can range in power and influence from the hegemonic narratives that form the bases of national identity to oppositional accounts of minority or individual experience (Ashplant et al. 2000, 16; Schulze 2004, 647). In many cases these narratives take their form, frames of reference, and, frequently, aspects of their content from pre-existing group or national narratives such as religious or nationalist origin myths. This borrowing and the consequent similarities can be a starting point for a challenge to dominant narratives, just as it can be a source of reinforcement (Ashplant et al. 2000, 17-20).

The oppositional form of memory narratives have been described as 'sectional narratives' (Ashplant et al. 2000, 20). Sectional narratives are expressions of group remembrance that have been articulated in a wider public sphere but have yet to gain official sanction or recognition. If the dominant political forces deem the sectional narrative incompatible with the official processes of remembrance then it may be marginalized or suppressed through the expression of hegemonic narratives (Dawson 2005). The varying levels of exclusivity, in narratives of war memory in particular, are closely linked to issues of group identity and social exclusion.

\section{Arenas of articulation}

Arenas of articulation refer to those socio-political spaces within which social actors advance claims for the recognition of specific war memories ... they range, in social breadth and political importance, from the networks of families or kinship groups ... to the public sphere of nation-states and transnational power blocs. (Ashplant et al. 2000, 17)

Arenas of memory articulation exist on different scales; the face-to-face groups already mentioned being the most abundant, and the most significant in the creation of collective remembrance:

When individuals can express and compare their memories with the experience of contemporaries, can begin to formulate a shared language and identify common themes, then what may be termed 'shared' or 'common' memories emerge. (Ashplant et al. 2000, 18)

These arenas of articulation include families, survivor groups, local communities and ex-service organizations (Dawson 2005).

Participation in these groups is, however, by no means inevitable. There are numerous situations in which individuals are reluctant or unable to form or take part in these arenas for psychological reasons, as in the case of many trauma victims with memories of loss or victimhood; or for social reasons, for example 
the exclusion or suppression of perpetrator groups (Ashplant et al. 2000, 20-21).

In the modern era, it has been the nation which has been the prime arena for the articulation of war memories and the mobilisation of commemoration, since war has been central to its identity and symbolic continuity. (Ashplant et al. 2000, 22)

The creation and re-imagination of war memory by national elites is a dynamic process: new wars are represented in terms of older, more popular ones, and sectional memory narratives are either incorporated or repressed. To enter into this public arena, all new memory narratives must be articulated in some form of cultural, political or artistic expression.

In the post-war era, and again in the post-Soviet era, a new arena of memory narration has gradually emerged on an international level. Debates around human rights violations, victimhood, reconciliation and compensation allow groups that have been excluded from national arenas to articulate their memory narratives (Ashplant et al. 2000, 25). These have met with varying degrees of success but in some cases, for example the International Criminal Court, they have influenced dominant narratives on national scales.

\section{Agencies of articulation}

The concept of agencies of memory articulation is absolutely crucial in any critical understanding of memory politics, examining the ways in which social actors advance and gain recognition for their narratives of memory. These agencies include state and non-state bodies, formal and informal movements in society, as well as the smaller groups discussed above (Dawson 2005).

Agencies of articulation generally operate from the top down: the actions of the nation-state influence or control almost all other agencies down to the individual level, but the memory discourse remains dynamic, constantly contested between agencies of unequal power and influence (Ashplant et al. 2000, 25-6). Subordinated groups challenge state commemoration of war in a number of ways, but Ashplant et al. identify two variables that constrain this process: the nature of the state; and the degree to which a conflict has been caused by or has led to internal division within a society or state $(2000,26-7)$.

In the first case, authoritarian or imperialist regimes tend to impose totalizing and inflexible narratives of war, while in democratic societies it has been suggested that a coherent shared memory is an impossibility, with debate increasingly taking place in the public sphere through the creation of material or ephemeral 'counter-monuments' (Young 1992; 1999). In some situations 'direct and pervasive control of war commemoration from above ... may serve to preserve private memory as a counter-force' (Ashplant et al. 2000, 30). In the second case, a shared narrative of the conflict may be imposed from above onto a shattered and divided nation, or a model based on reconciliation and justice might be introduced as a healing process: again this depends on the nature of the society.

Between the state and its different levels of agency on the one hand, and family and kinship groups on the other, there is an intermediate set of agencies formed by shared or analogous memories of war and conflict. These are principally ex-service organizations, based on service within a unit, a theatre of combat, or shared physical or psychological disabilities arising from the war (Ashplant et al. 2000, 29). The ability of these transitional agencies to challenge official narratives or to take part in their creation depends on several factors, but in many cases they have been successful: the Whitehall Cenotaph was only made into a permanent memorial after pressure from ex-service groups and families of fallen soldiers (Moriarty 1995). It is important to reiterate the distinction between these and other groups as arenas or articulation, where memory narratives are formed, and as agencies of articulation, through which these narratives are projected upwards.

These elements of memory articulation form part of a larger and impressively comprehensive scheme of memory work outlined by Ashplant et al. (2000; Dawson 2005; Schulze 2004). Schulze identifies two key processes within this model relating to the articulation of memory narratives. The first focuses on the bottom-up process whereby individuals' memory narratives move into the public arena, while the second focuses on agencies of articulation from the top-down, starting with the state and ending with the individual (Schulze 2004, 646-7). While Schulze's analysis of this model is somewhat simplistic it highlights many of its strengths, particularly its applicability beyond the extreme examples of war or conflict memory to the wider memory project:

Such a framework of arenas and agencies makes it possible to include issues such as the subjectivity of individual memory; generational transmission; the employment of established 'templates' or figurative patterns in the articulation of memory and the role of the historian in creating and maintaining these; the official politics of commemoration, and shifts in national and transnational 'master narratives'. (Schulze 2004, 647) 
Ashplant et al. highlight the value of their model in unpicking the relations of power and resistance that underlie all memory discourses, suggesting that:

analysing specific instances of war memory and commemoration in these terms can help to clarify its politics, by specifying which social groups, via what agencies, are the promoters of a particular narrative addressed to which arenas. (Ashplant et al. 2000, 17)

Mnemonic communities and intersubjectivity Our understanding of the different forms of memory communities can draw on the model outlined above to examine how groups that are principally arenas of memory articulation can form agencies of articulation to project their narratives into a larger arena. A brief examination of this theory of memory suggests that memory work and archaeological work on sites of recent conflict are inextricably linked. Archaeological findings will inevitably influence the creation and recreation of memory narratives, while the public interest in the site itself can lead to the excavation becoming an arena of articulation and negotiation. Finally, the unusual relations of production of knowledge in archaeology may help these communities to form agencies of articulation based around the fieldwork processes and the site. These issues are discussed and developed in the remaining part of this article. For now, it is useful to consider different conceptions of the memory community that have been proposed in relation to the memory of war or conflict, before looking at some of the ways in which war memory is different, and whether work in this field can be used more widely.

The concept of the 'mnemonic community' as defined by Cappelletto focuses on the face-to-face level of everyday interaction within spatially coherent heterogeneous groups (2005). It is important to note that 'community' in this and other definitions is both an etic and an emic term, as this takes into account the perspective of the historian or ethnographer as well as the individuals who 'see themselves as being a mnemonic community with reference to past events: the filter which they look through when remembering' (Cappelletto 2005, 6). Cappelletto's study focuses on memory of warfare in small, mainly rural communities, often divided into victim and perpetrator groups, and recognizes the prevalence of victim or survivor groups among the mnemonic communities that are the principal focus of research. She also highlights the impact of focusing on these small groups in personalizing histories of conflict and introducing agency into narratives of violence and atrocity (Cappelletto
2005, 6). Most importantly, Cappelletto highlights the diversity that can exist within a memory community, and its significance:

If mnemonic communities are constructed by recalling a shared past, they are not understood here as corporate groups, as politically and ideologically unified wholes ... community does not mean the absence of conflicts and political rivalry within the local unit. On the contrary, divided memories often play an important part in the process by which people try to come to terms with their past and to metabolize the traumatic effects of past violence. It is this aspect which sets apart local memories from the grand narrative of the nation-state about a united resistance. In fact, local group memories may even develop into a counter-discourse consciously opposed to that grand narrative. (Cappelletto 2005, 6-7)

In terms of the model suggested by Ashplant et al., Cappelletto identifies geographically defined communities as arenas of memory negotiation, and highlights the possibility of emerging local group agency. Equally, she raises the problems of dissonant memories within survivor groups, the fragility of collective remembrance in these contexts, and the ethical burden this places on the historian or ethnographer (Cappelletto 2005, 7). This ethical element is less clearly articulated in other formulations of memory work; it also raises important issues for archaeological memory work, particularly that which explicitly aims to introduce a discordant element into the memory arena (Moshenska 2008).

In the course of this analysis of local memory, Cappelletto revisits the issue of intersubjectivity raised by Winter \& Sivan. In the context of collective remembering, intersubjectivity is understood as the process based on empathy and mutual recognition through which individuals within a group come to a shared understanding of issues or ideas:

while the notion of collective is abstract, the intersubjective, it is argued, is incorporated: 'incorporated memories' are the plurality of those particular memories which make a social time-space into something familiar. (Cappelletto 2005, 10)

\section{Geographies of memory}

Dawson's development of the model outlined by Ashplant et al. introduces a spatial and geographical element, examining 'the formation of "cultural landscapes", spatial identity and sense of belonging in a particular place, and local place-based forms of memory and commemoration' (Dawson 2005, 155). This focuses on the creation of mnemonic communities based on geographically defined groups; clearly this conception of collectivity is of no small interest 
to an archaeologist working with memory, landscape and material culture. Dawson suggests that different physical spaces can become associated with the process of enacting memory and commemoration to the extent that control of these spaces becomes a primary aim of the agencies of memory. Where memories of conflict are concerned, this can include the creation of spatial identities through designating spaces which are 'ours' and spaces which are 'theirs' (Dawson 2005, 155).

The idea of spatial memories and identities draws on anthropological ideas of space to distinguish between material 'places' constructed and understood on a social level; 'cultural landscapes' created through collective remembrance; and the internalized 'sense of place' formed from personal experiences and private memory. Dawson focuses on Northern Ireland to demonstrate how community-based acts of remembrance centred around significant places can drag repressed memories of trauma to the surface.

In this process, psychic 'sites of trauma' are formed within the internal landscape, that are derived from - and complexly related to - the material sites of violence within social environments, together with the meanings and memorial markers that constitute cultural landscapes of violence, horror, and mourning. Memories of traumatic events commonly focus on, and return in imagination to, the sites where they 'took place'. (Dawson 2005, 156)

By tracing memory and trauma onto the landscape, Dawson highlights the ways in which different mnemonic communities can experience places in entirely different ways, leading to polarization within the local population. This in turn makes the ownership and control of these spaces a factor in the struggle between dominant and privatized memory narratives, adding a spatial dimension to the conflict. Conversely, it also raises the possibility that 'commemorative practices focused on local sites of trauma [might] contribute towards "coming to terms with the past" (Dawson 2005, 156). This has obvious implications for a putative archaeological approach to conflict sites.

\section{Warfare and mnemonic communities}

The remembrance of war and conflict has played a unique and powerful role within memory studies; this work has focused on the destructive, transformative and traumatic nature of war and its impact in individuals and societies:

The subject of war has dominated the memory boom for a host of reasons. It is not just the injuries of war, but its drama, its earthquake-like character, which has fuelled the memory boom. (Winter 2006, 6)
It is worth considering the divisive effect of warfare on local communities, and the polarized mnemonic communities that are one of the defining characteristics of war memory.

Amongst the distinctive social effects of warfare is the creation of new categories of individual and group identity, and the increased importance of existing ones. In the aftermath of conflicts these categories can often be usefully linked to distinctive mnemonic communities; again the definition of these groupings can be emic or etic. The fragmentation of society in wartime is reflected in the numerous overlapping mnemonic communities defined by age, gender, occupation (war work/non-war work), rural/urban and so on. This is exacerbated by the power of wars to fracture and scatter populations, both by force in the face of advancing armies, and by social or economic pressure as with refugees who choose to move abroad rather than return to shattered homes.

Memory work focusing on groups or communities often takes place on an individual level, based on one-to-one interviews with a historian or ethnographer; the complexities outlined above introduce both a practical and an ethical consideration into this work. The interviewer needs to be aware that the person they are talking to is situated within a mnemonic community with complex relationships to other members of that group as well as to other groups: it must be remembered that interviews and memory projects in general can be powerful arenas of memory articulation, and that a variety of agencies will try to make use of them to promote their sectional narratives. The implications of this for both the archaeological work and research in general is discussed in the third section of this article.

\section{Crises of memory}

What happens when agencies of memory articulation clash? Put another way, what is the outcome when a sectional memory narrative projected upwards into the public sphere comes into direct conflict with a dominant narrative imposed onto a population? Sulieman characterizes this as a 'crisis of memory', in which

individual self-representation overlaps with - and sometimes becomes the crux of - collective selfrepresentation; put another way, individual remembrance takes on collective significance, occasionally becoming a conflicted 'affair of memory'. (Sulieman 2006, 1)

The use of the term 'affair' highlights the importance of both political interference and media representations in these conflicts of memory articulation. Most 
importantly crises of memory are located within existing arenas of memory articulation:

At issue in a crisis of memory is the question of selfrepresentation: how we view ourselves, and how we represent ourselves to others, is indissociable from the stories we tell about our past. (Sulieman 2006, 1)

Crises of memory become affairs of memory when the struggle moves beyond the limits of the arena into the public sphere; the conflict itself becomes a memory narrative. In the case of the Second World War, crises of memory have erupted into the public sphere with some regularity, from the Nuremberg tribunals of 1946 through to the present day.

Many of these crises of memory around the world from America to Japan have focused on controversial representations of the Second World War in films, literature and scholarly research. In Canada, the screening of a documentary about the bombing of Germany and the role of Canadians in the RAF led to an investigation by the Senate, prompted by outrage amongst veteran groups in which the filmmakers came under sustained attack (Carr 2003). The Wehrmacht exhibition in Hamburg in 1995 created a scandal by confronting the German people with evidence that regular soldiers as well as the SS had taken part in atrocities and extermination actions on the Eastern Front, tearing down a comfortable and widely accepted popular memory narrative (Wildt et al. 2004). In 1997 the trial in France of suspected collaborator Maurice Papon raised sensational if scurrilous accusations that Raymond and Lucie Aubrac, celebrated heroes of the resistance, had in fact been informers for the German occupiers: one in a series of attacks over the years on French popular memory of resistance and collaboration (Sulieman 2006, 36-7). In all of these cases it is conservative popular memory narratives fostered by the state and widely accepted by the population that are under attack by radical historians; from the left in Canada and Germany, and from the far right in France.

Inevitably formal commemorative practices of various kinds have led to crises of memory. Ronald Reagan's controversial 1985 visit to the cemetery at Bitburg where SS men were buried raised protests from Jewish organizations and veteran's associations in the USA and elsewhere (Spitzer 1996), while in Japan senior politicians continue to visit the Yasukuni shrine to reinforce their conservative nationalist credentials in the face of international outrage. The international elements of these and many similar examples complicates the discourses of dominant and subordinate memory narratives, as in contrast to the previous examples these commemorative practices are orchestrated by agencies of the state and the protests are generally from other countries.

It is notable how many crises of memory crystallize around material culture, including the monuments mentioned above, other forms of memorials, museum displays and objects of various kinds. The most notorious example of this is the B29 Superfortress Enola Gay which dropped the atomic bomb on Hiroshima, and its display in the Smithsonian in Washington. The initial exhibition included information on the aftermath of the bombing including images of injuries and destruction. The reaction from the public, politicians, veterans groups and the media was overwhelming, and the museum was forced to tone down the display, focusing not on Japanese casualties inflicted but on American casualties allegedly avoided (Gieryn 1998, 204; Hogan 1996).

A more recent crisis of memory has seen the breaking of the longstanding Pacto del Olvido or pact of silence around the atrocities of the Spanish Civil War, specifically the murder of hundreds of thousands of civilians and prisoners during and after the conflict, primarily by the Francoist Nationalists (Davis 2005). The silence imposed on the families of the victims, first by the fascist state and later by political consensus during the transition to democracy, has gradually ended with a high-profile and highly controversial programme of exhumations, focusing on mass graves of murdered Republicans. These excavations, which began in 2000 and grew in number following the 2004 election of a socialist government, have stimulated and shaped the debates around Spanish Civil War memory that have begun to emerge in the public and political spheres (Davis 2005, 859; González-Ruibal 2007). The archaeological excavation of these murder sites continues to play a powerful and problematic role in these mnemonic processes (Congram \& Steadman 2008).

\section{Archaeological interventions into memory}

The aim of this section is to examine the idea that archaeological fieldwork can create an arena of memory based around a particular site and locale. This raises a number of issues concerning the validity and uses of this comparison, its limitations and its practicalities. In a more general sense, this section considers some of the ways in which archaeological sites and their environments can provide opportunities to observe and participate in the processes of memory negotiation, articulation and contestation. In an attempt to illustrate and further explore these points, and the processes outlined in this article, I will 
first outline an example of modern conflict archaeology that took place in West Berlin in the 1980s.

\section{'Let's Dig!': an archaeological arena of memory in West Berlin}

The Active Museum of Fascism and Resistance in Berlin, Inc., and the Berlin History Workshop, Inc., will try to draw attention to the history of the terrain at Prinz-Albrecht-Palais at 11am on Sunday, May 5, 1985. This will be done by means of a commemorative operation on the site. (in Rürup 1996, 214)

Between 1933 and 1945 Prinz-Albrecht-Strasse in Berlin, close to the government quarter, became the home of Nazi Germany's most notorious organizations: the Gestapo, the Security Service (SD) and the SS Reich leadership (Till 2005). From these offices the deskbound murderers or Schreibtischtäter planned and administered the Nazi programmes of persecution, oppression, forced labour and genocide. In the cells below the office buildings political prisoners and other enemies of the state were imprisoned, interrogated and tortured by the Gestapo.

By 1945 this heartland of the Nazi empire had been badly damaged by Allied bombs and Red Army shells; the buildings stood empty into the 1950s when many were demolished. Several scholars have questioned the motivation for this destruction: while the official excuse was the structural weakness and dilapidation of the buildings, others nearby with worse damage but without such dark histories were left standing (Till 2005, 76). These demolitions marked the first inscriptions of the dominant historical narratives of amnesia onto the landscape of West Berlin. By 1963 the Prinz-Albrecht-Strasse terrain had become a rubble processing area and an 'autodrome' for learnerdrivers (Baker 1988, 96-7).

The first proposals for redeveloping the site came in 1957 as part of a Berlin Senate campaign to make Berlin a 'modern international city' (Baker 1988, 97). This plan collapsed in the wake of the construction of the Berlin Wall in 1961. The first scheme to include a commemorative element emerged in 1982, when the Social Democratic Party proposed an architectural competition to design a memorial to the victims of fascism on the site. The competition attracted a number of entrants, including two from East Berlin who were imprisoned for their attempted involvement in a West German project. In 1983 the winners of the competition were announced, but within a year the local government had changed hands, and the right-wing Christian Democratic Mayor of West Berlin cancelled the commemoration project (Baker 1988, 100). Once again the buried remains of the Nazi past became a screen onto which divergent historical viewpoints of remembering and forgetting could be projected.

In 1985, with the future of the site still uncertain, citizen groups began to take action: the Active Museum of Fascism and Resistance in Berlin and the Berlin History Workshop planned a series of protest activities. The Active Museum was an alliance of organizations and individuals, including former anti-Nazi activists, artists, historians, architects, and activists from the umbrella Green-Alternative List, as well as the evangelical academy and the GermanSoviet friendship society (Till 2005, 93).

Operation Let's Dig! was launched on 5 May 1985, when a large group of protestors occupied the Prinz-Albrecht-Strasse site and conducted a guerrilla excavation, removing turf, topsoil and rubble from the site of the Gestapo prison buildings. While bereft of trained archaeologists the excavation team included former prisoners of the Gestapo who had been held at Prinz-Albrecht-Strasse during the Nazi period. The dig was intended as a symbolic and demonstrative act, embodying the slogans of the groups involved: 'GRASS MUST NEVER BE ALLOWED TO GROW OVER IT' and 'THE WOUND MUST STAY OPEN' (Baker 1990, 58). The timing of the dig, including it's 11am start, deliberately coincided with the fortieth anniversary of the Russian conquest of Berlin, described by the Active Museum as 'liberation from Nazi fascism' (in Till 2005, 95). The Let's Dig! project built on the Swedish History Workshop model, where the expression 'Gräv där du står' or 'Dig Where You Stand' was used as a metaphorical battle-cry for local historical studies of workplaces and homes carried out by amateur researchers.

On the basis of this illegal project a further, official excavation of the site was carried out the following year, although as before there were no archaeologists involved, for reasons that are unclear. This project uncovered the foundations of the Gestapo detention cells, whereupon proposals for a memorial were shelved in favour of an interpretation centre on the site. This exhibition, titled Topography of Terror, was initially intended to be temporary. It was still there when I first visited the site on a school trip in 1996, and it is still there today under the care of the Topography of Terror Foundation.

The Let's Dig! project has been studied and interpreted in a number of ways. Baker $(1988 ; 1990)$ used it to illustrate Habermas's theory of communicative action in archaeology, while Bernbeck \& Pollock (2007) highlight the focus on perpetrators in the exhibition, although the theoretical bases of 
the initial excavations rather undermine their argument. Till rather bewilderingly regards the project as an attempt to 'resituate and recombine texts, signs, things, and locations ... in which past, present, and future were understood as co-constituitive' $(2005,95)$. My interest in the project lies in the degree to which it exemplifies the framework of memory dynamics outlined in this article: the formation of narratives within inter-subjective communities; the formation of agencies to articulate these narratives; and the creation and exploitation of social arenas, based on archaeological excavations, in which the narratives can be promulgated.

\section{Archaeological memory arenas}

To what extent, then, can an archaeological site such as the Prinz-Albrecht-Strasse site constitute or contribute to the creation of a memory arena? Firstly, let us review the notion of the arena of memory articulation as formulated by Ashplant et al. (2000) and developed by Dawson (2005): a collectivity or social space in which memory narratives are formed, asserted and contested. The wide range of scales of arenas of memory reflect the variety of functions that they serve. On a small-scale intersubjective level they are the forum for individuals to articulate their own memory narratives; the first stage in the transformation of personal memories into narratives of collective memory. When these groups or individuals form agencies to promote their memory narratives the discourse moves into a broader public arena on a local, national or international scale.

Firstly it is important to recognize that in the case of the Prinz-Albrecht-Strasse site subaltern historical narratives were formed and promoted in explicit opposition to hegemonic narratives of amnesia and the erasure of physical traces of an uncomfortable past: what Macdonald has called the 'undesirable heritage' of the Nazi past in Germany $(2006,9)$. In early 1980 s West Berlin the dominant narrative swung away from commemoration of the Nazi era: more precisely, it moved from an admittedly half-hearted focus on perpetrators towards an anodyne and essentializing emphasis on victims and victimhood (Bernbeck \& Pollock 2007, 222). The agencies employed by the promoters of these histories and their elected representatives were legislation and the exercise of political power.

In opposition to this process, a wide and diverse range of individuals and groups came together to form an agency for the articulation of their own, subaltern memory narratives: out of this process the Active Museum was created. While there was undoubtedly a degree of heterogeneity within this group it success- fully promoted a clear and consistent line: that the victims of Nazi oppression should be commemorated in the heart of Berlin, and that this process could not be a comfortable one. The final stage was to create a public arena for the articulation of this narrative. It is interesting and highly relevant that a group without any obvious archaeological background should conceive of an excavation as the best form of arena. There are numerous possible activities and performances whereby a historic site can be inscribed or re-inscribed with power and significance. The Active Museum, with its glass floor panels covering excavated remains, chose archaeology.

It is important to note the distinction between the 'social space' of the theorized memory arena and the physical space of the archaeological site. The link between the two emerges from Dawson's analysis of contested sites of memory in Northern Ireland. Dawson considered the processes whereby symbolic ownership or control of a contested site or landscape and the attribution of significance is argued on the basis of individual and collective memories:

Following the turn towards spatial and geographical paradigms in Cultural Studies, I have become interested in the intersection of these processes with the formation of 'cultural landscapes', spatial identity and the sense of belonging in a particular place, and local place-based forms of memory and commemoration in key locations of the Troubles. Our understanding of conflicts over the remembered past may be deepened by integrating theories and methods developed by social anthropologists and cultural geographers to investigate the subjective identities, meanings and memories that become attached to, and invested in, the objective, physical spaces of the social world. ... Spatial identity, based on feelings of belonging in a place, develops over time as 'layers of meaning' and remembered associations accrue to a location in the course of everyday life. The 'identifiable sites' formed in this way are shaped by the emotional investments made in them, but also by 'wider issues of power, group dynamics, conflicting ideologies and institutions', that affect 'both the physical appearance of places ... and the way they are conceptualized'; giving rise to disputes over the possession of territory, and to what the Australian cultural geographer and historian, Peter Read, has called 'contested attachments' to the same place. (Dawson 2005, 155)

The frequency and fervour with which individuals and groups claim ownership of spaces and landscapes supports Dawson's proposed conflation of memory, power, ideology and site, and reinforces the significance of the Prinz-Albrecht-Strasse excavation site as both a physical and a social space. 
Points of correspondence and non-correspondence What is the impact of an archaeological intervention in cultural landscapes invested with meaning? What effect does this often destructive means of research have on the power relations and ideologies that underlie the commemorative practices and processes associated with the sites? In what ways does the archaeological site become a means to create meaning and symbolic capital within different mnemonic communities? To address these questions in more depth it is necessary to enumerate and discuss the points of correspondence between archaeological and mnemonic spaces, as well as the points of divergence and more generally the assumptions that underpin my model.

The most fundamental connection between archaeological sites and Dawson's sites of memory is their function as socio-political spaces within which knowledge is created and transmitted (Tilley 1989). As such they embody relations of production of knowledge that can be contested, manipulated and studied (Nora 1989; Yarrow 2006). Studies of spaces or sites of memory, particularly those that take an ethnographic approach, tend to focus on social dynamics and power relations within a clearly defined area or group (e.g. Cappelletto 2005). A number of studies in the nascent field of ethnographies of archaeology take a similar approach in examining the relations of power, personality and knowledge within archaeological projects (Edgeworth 2006; Breglia 2006). The conjunction of these approaches offers insights into the correspondences between mnemonic and archaeological social spaces, as well as possible methodologies for studying them in practice.

The inherent fluidity of the concept of spaces or arenas of memory, flitting between the physical and the socially constructed, allows a broader analysis of the archaeological site of memory intervention. Rather than crudely equating the performance of an excavation with, for example, a commemorative practice associated with a site or landscape of significance, this wider viewpoint recognizes the enduring significance of the archaeological project within the community or locale. As the Prinz-Albrecht-Strasse site demonstrated, a proposed or planned archaeological intervention is often itself an arena or catalyst for contestation; equally a closed excavation can be a focal point for processes of memory and commemoration focused on the site itself or the resulting archival, museum or educational resources (Rürup 1996).

Arenas of memory articulation function at a range of scales, as already noted, from the kinship group to the nation state and beyond. On a functional level only the smaller end of this scale correspond to the spatial scales of archaeological sites: families, face to face communities and small- to medium-sized geographic communities. However, two important points emerge from this: firstly, these are the scales at which individual memories are expressed, discussed and forged into narratives of group remembrance. Secondly, the spectacular nature of the archaeological site can bring together people from a wider area than might normally interact, creating a novel intersubjective arena on an unusually large scale.

One of the more interesting if problematic characteristics that link arenas of memory with archaeological sites is mediation. Sites of socio-political significance are a very common theme in artistic and other cultural representations ranging from paintings and popular music to advertisements and propaganda (Samuel 1994). Similarly, for most people archaeology is experienced through the medium of television, newspapers and magazines rather than as a practice located solidly in their own environment (Moshenska 2006). However, for the communities around the contested conflict archaeological sites, mediation is unlikely to be an issue either in the formation of memory narratives or in their experiences of the archaeological process.

One of the key points of non-correspondence between archaeological arenas of memory and sites of memory is their origins or source. While sites of memory and arenas of memory articulation are very often spontaneous reactions to situated events, archaeological interventions are often imposed on communities with little or no consultation; the different sources of archaeological work are discussed below. Grass-roots archaeological projects on sites of memory remain rare, although the Prinz-AlbrechtStrasse excavation offers one example. In this respect the majority of archaeological interventions on sites of memory are expressions of the power of certain agencies of memory articulation such as social, cultural or political elites; in effect commemorative practices aimed at perpetuating hegemonic historical narratives.

The proposal that an archaeological site can function as an arena of memory articulation assumes a degree of popular engagement and involvement. In many respects this is a fairly safe assumption, as popular interest in and support of archaeology in general is high: the phenomenon of archaeo-appeal identified by Holtorf (2005) shows how cultural representations of archaeology both reflect and perpetuate this. However, on sites of contested or traumatic memory popular engagement cannot be guaranteed; although 
it should be born in mind that violent opposition to the archaeological work is itself a revealing response. My own fieldwork to date has found an overwhelming interest in conflict archaeology even on sites of traumatic memory; it remains to be seen whether results will be consistently this encouraging.

One possible criticism or weakness of the model I have outlined is that the terms and concepts that I am working with, for example site, archaeology, memory and significance are too broad and inclusive, with little chance of drawing clear conclusions or faulting my initial assumptions. My general and uncontroversial hypothesis is that archaeological work on sites of recent conflicts will impact in some way on the mnemonic processes associated with those sites. I have suggested a framework for analysing the dynamics of this relationship, and the beginnings of a methodology, developed in more depth below. However it is vital that these basic premises be subject to continued critique, particularly as they include terms such as archaeology and memory that are frequently and unwisely used as metaphors, quite often together (cf. Holtorf 2005; Wallace 2004).

Another more valid criticism of this project is that archaeological interventions into sites of traumatic and contested memory may have extremely adverse results including causing distress to traumatized individuals or resurrecting inter- or intra-community conflicts. These factors are what makes it necessary to outline in detail a set of appropriate methodological, theoretical and ethical frameworks within which this work can take place (Moshenska 2008). This work will inspire anger and distress; it is up to the researchers to do so consciously and responsibly.

\section{Public archaeologies of memory}

So far the archaeological half of the equation has remained conveniently vague; now it is time to ask: what kind of archaeological research environment does this model presuppose, what relation does it bear to reality and what are the main logistical and practical issues to be considered? In general, the public archaeology I am proposing is open, socially engaged, reflexive, spectacular and performative. Like a model I have outlined previously (Moshenska 2006), it is based on a conception of the archaeological site as a performance space as well as a research space, with archaeologists as actors and the public as an audience, actively engaged in the processes of knowledge creation (Tilley 1989). The performative aspect of archaeology is one that the Active Museum in Berlin grasped from the start. The key point that differentiates work on sites of recent conflicts from other public archaeology is the nature of its audience. In much of this work the audience are a primary resource, they form the social context within which the work takes place, and they frequently participate in the research process. Clearly the traditional distinctions between performers and audience cannot apply here.

A public archaeology based on these ideas is one that is consciously and proactively open and accessible to the public, that demonstrates the importance of the knowledge that local people bring to the site by making an effort to collect and study it, and reflects these values in the dissemination of information both during and after the fieldwork itself. While they vary considerably according to the scale of the project, the logistics and practicalities of such a system are daunting. The memory work is a central component of a public archaeological project of this kind: this can take a variety of forms including oral history interviews, coordinating public events of commemoration, studying the ways in which people who remember the conflict interact with the archaeological site, and transforming the memory narratives that are collected into educational resources.

The biggest problem with this proposed model is its almost total irrelevance to the vast majority of archaeological work that takes place. Up to this point I have focused my attention on the rare phenomenon of research-driven archaeological projects on sites of recent conflict, ignoring the fact that the vast majority of work on these sites is driven by rescue archaeology or resource management with little or no public involvement. This disconnection is a common problem in a great deal of public archaeology, and more generally within theoretical archaeology.

\section{Agency and the archaeologists}

In recognizing that the various mnemonic communities will have different socio-political agendas to promote I do not wish to give the impression that the archaeologists and other researchers involved are or can be in any way neutral. The researchers have enormous power and control over which mnemonic narratives are articulated and which are not; there is a high likelihood that this power will either be misused or co-opted. For these reasons critical self-awareness is a crucial element of observer/participant research of this kind. In this context it is necessary to consider the best approaches to the research that, while recognizing the agency of the archaeologists, will produce interesting and valuable results without creating dangerous divisions and tensions within the communities in question.

Without a doubt the most interesting and subversive feature of these public archaeologies of 
conflict memory is their ability to subvert existing power relations, creating an environment of memory negotiation which, while far from egalitarian, is more open and democratic than most other forms. The greatest obstacle to this unrestricted poly-vocality is the often well-intentioned direct intervention of the archaeologists. I am under no illusions that the study of mnemonic processes through archaeological work on sites of recent conflict is anything other than controversial, extremely subjective, difficult to instigate and even harder to interpret. The aim of the researchers should therefore be to create an environment of research that is inclusive without being chaotic, open without being vulnerable to exploitation, accessible without becoming bland or simplistic, and interesting and enjoyable enough that people want to get involved.

\section{Discussion}

In this article I have argued that archaeological approaches to contested conflict heritage are a mechanism whereby sites, artefacts and bodies can be made public, powerful and resonant. The case of the Prinz-Albrecht-Strasse site emphasizes the potential strengths of this approach, particularly for the promotion of subaltern or suppressed historical or mnemonic narratives.

The ideas that I have expounded and explored have their roots in fieldwork I carried out on two Second World War sites in London and Poland in 2003. In this work I encountered the combination of extraordinary material culture, first-hand memory narratives, and a keen public audience for archaeology that fired my interest in these peculiar encounters and my awareness of their potential power and significance. The affective power of these archaeological interventions into memory and the strength of the emotions that they drew out also made a strong impression, highlighting in particular the weaknesses and missed opportunities of a superficial understanding of conflict memory, trauma and contestation.

My aim in this work has been to develop an understanding and appreciation of memory work in the archaeology of recent and contemporary conflicts, and the impact that an archaeological perspective can have on the processes of memory. I have explored these ideas in two ways: firstly, by developing what I believe to be a sound model of memory dynamics on a realistic operational scale; and secondly by looking at the different ways in which archaeological work can interact with these processes. I have tried to emphasize the importance and relevance of this work as a solid foundation in theory and proposed methodology for what I fully expect to be a difficult and controversial field of study.

The models of archaeological research I have advocated and explored in my case study are based on a particular model of public archaeology or more specifically community archaeology. This model, incorporating high levels of public involvement and interaction, popular publishing and other forms of communication, and an underlying principle of democratic openness and inclusivity is, I realize, a minority practice within archaeology. However I have been privileged to have worked in this context of community archaeology from my very first digs and to have carried it on in the fieldwork I now coordinate. Therefore what might appear to be a rather whimsical view of archaeological fieldwork is in fact the one which is most familiar to me and where my area of expertise lies (e.g. Moshenska 2007).

As well as providing conflict archaeology with a rigorous foundation in memory theory, this article aims to show some of the contributions that archaeology might make in return, including the idea of site-based research as a commemorative practice on sites of contested memory and a proactive, agent-led approach to arenas of memory articulation. I hope that these ideas that I have outlined will be of interest to researchers in other fields, leading to even more interesting interdisciplinary approaches to contested sites of war and conflict memory.

\section{Acknowledgements}

An earlier version of this article was presented at the 2006 Contemporary and Historical Archaeology in Theory conference in Bristol. My thanks to Tim Schadla-Hall, Victor Buchli, John Schofield, Nick Saunders, Neil Faulkner, Layla Renshaw, Howard Williams, Adrian Myers, Martin Brown, Paola Filippucci, Alfredo González-Ruibal and Jon Price for stimulating discussions of conflict memory and commemoration. I am indebted to Chana Moshenska, Raf Salkie and the anonymous referees for extensive comments on earlier versions of the paper. This research was funded by the Arts and Humanities Research Council.

Gabriel Moshenska Institute of Archaeology University College London 31-34 Gordon Square London WC1H OPY $U K$ Email: g.moshenska@ucl.ac.uk 


\section{References}

Ashplant, T.G., G. Dawson \& M. Roper, 2000. The politics of war memory and commemoration: contexts, structures and dynamics, in The Politics of War Memory and Commemoration, eds. T.G. Ashplant, G. Dawson \& M. Roper. London: Routledge, 3-85.

Assman, J., 1995. Collective memory and cultural identity. New German Critique 65, 125-33.

Baker, F., 1988. History that hurts: excavating 1933-1945. Archaeological Review from Cambridge 7(1), 93-109.

Baker, F., 1990. Archaeology, Habermas and the pathologies of modernity, in Writing the Past in the Present, eds. F. Baker \& J. Thomas. Lampeter: St David's University College, 54-62.

Beck, C.M., J. Schofield \& H. Drollinger, 2009. Archaeologists, activists, and a contemporary peace camp, in Contemporary Archaeologies: Excavating Now, eds. C. Holtorf \& A. Piccini. Frankfurt am Main: Peter Lang, 95-111.

Bergson, H., 1988. Matter and Memory. New York (NY): Zone Books.

Bernbeck, R. \& S. Pollock, 2007. Grabe, Wo Du Stehst! An archaeology of perpetrators, in Archaeology and Capitalism: From Ethics to Politics, eds. Y. Hamilakis \& P. Duke. Walnut Creek (CA): Left Coast Press, 217-34.

Black, J., 2004. Thanks for the memory: war memorials, spectatorship and the trajectories of commemoration 1919-2001, in Matters of Conflict: Material Culture, Memory and the First World War, ed. N.J. Saunders. London: Routledge, 134-48.

Bourke, J., 2004. Introduction: 'remembering' war. Journal of Contemporary History 39(4), 473-85.

Breglia, L., 2006. Complicit agendas: ethnography of archaeology as ethical research practice, in Ethnographies of Archaeological Practice: Cultural Encounters, Material Transformations, ed. M. Edgeworth. Lanham (MD): Altamira, 173-83.

Cappelletto, F., 2005. Introduction, in Memory and World War II: an Ethnographic Approach, ed. F. Cappelletto. Oxford: Berg, 1-25.

Carr, G., 2003. War, history and the education of (Canadian) memory, in Contested Pasts: the Politics of Memory, eds. K. Hodgkin \& S. Radstone. London: Routledge, 57-78.

Confino, A., 1997. Collective memory and cultural history: problems of method. American Historical Review 1386-403.

Congram, D. \& D.W. Steadman, 2008. Distinguished guests or agents of ingérence: foreign participation in Spanish Civil War grave excavations. Complutum 19, 161-73.

Connerton, P., 1989. How Societies Remember. Cambridge: Cambridge University Press.

Crossland, Z., 2000. Buried lives: forensic archaeology and the disappeared in Argentina. Archaeological Dialogues $3,146-59$.

Crossland, Z., 2002. Violent spaces: conflict over the reappearance of Argentina's disappeared, in Matériel Culture: the Archaeology of Twentieth Century Conflict, eds. J. Schofield, W.G. Johnson \& C.M. Beck. London: Routledge, 115-31.

Davis, M., 2005. Is Spain recovering its memory? Breaking the Pacto del Olvido. Human Rights Quarterly 27, 858-80.

Dawson, G., 2005. Trauma, place and the politics of memory: Bloody Sunday, Derry, 1972-2004. History Workshop Journal 59, 151-78.

Edgeworth, M., 2006. Multiple origins, development and potential of ethnographies of archaeology, in Ethnographies of Archaeological Practice: Cultural Encounters, Material Transformations, ed. M. Edgeworth. Lanham (MD): Altamira, 1-19.

Edkins, J., 2003. Trauma and the Memory of Politics. Cambridge: Cambridge University Press.

Fentress, J. \& C. Wickham, 1992. Social Memory. Oxford: Blackwell.

Fraser, A.H. \& M. Brown, 2007. Mud, blood and missing men: excavations at Serre, Somme, France. Journal of Conflict Archaeology 3, 147-71.

Gedi, N. \& Y. Elam, 1996. Collective memory - what is it? History and Memory 8(1), 30-50.

Gieryn, T.F., 1998. Balancing acts: science, Enola Gay and history wars at the Smithsonian, in The Politics of Display: Museums, Science, Culture, ed.S. Macdonald. London: Routledge, 197-228.

González-Ruibal, A., 2007. Making things public: archaeologies of the Spanish Civil War. Public Archaeology 6, 203-26.

Green, A., 2004. Individual remembering and 'collective memory': theoretical presuppositions and contemporary debates. Oral History 35, 35-44.

Halbwachs, M., 1992. On Collective Memory. Chicago (IL): University of Chicago Press.

Hodgkin, K. \& S. Radstone (eds.), 2003. Contested Pasts: the Politics of Memory. London: Routledge.

Hodgkin, K. \& S. Radstone, 2005. Rethinking memory: introduction. History Workshop Journal 59, 129-33.

Hogan, M.J., 1996. The Enola Gay controversy: history, memory and the politics of presentation, in Hiroshima in History and Memory, ed. M.J. Hogan. Cambridge: Cambridge University Press, 200-232.

Holtorf, C., 2005. From Stonehenge to Las Vegas: Archaeology as Popular Culture. Lanham (MD): Altamira.

Huyssen, A., 1995. Twilight Memories: Marking Time in a Culture of Amnesia. London: Routledge.

Kansteiner, W., 2002. Finding meaning in memory: a methodological critique of collective memory studies. History and Theory 41(2), 179-97.

Klein, K.L., 2000. On the emergence of memory in historical discourse. Representations 69, 127-49.

Macdonald, S., 2006. Undesirable heritage: fascist material culture and historical consciousness at Nuremberg. International Journal of Heritage Studies 12(1), 9-28.

McAtackney, L. \& M. Palus, 2007. Introduction, in Contemporary and Historical Archaeology in Theory: Papers from the 2003 and 2004 CHAT Conferences, eds. L. McAtackney, M. Palus \& A. Piccini. Oxford: Archaeopress, 5-9.

Moriarty, C., 1995. The absent dead and figurative First 
World War memorials. Transactions of the Ancient Monuments Society 39, 7-40.

Moshenska, G., 2006. The archaeological uncanny. Public Archaeology 5(2), 91-9.

Moshenska, G., 2007. Oral history in historical archaeology: excavating sites of memory. Oral History 35(1), 91-7.

Moshenska, G., 2008. Ethics and ethical critique in the archaeology of modern conflict. Norwegian Archaeological Review 41(2), 159-75.

Nora, P., 1989. Between memory and history: Les Lieux de Mémoire. Representations 26, 7-25.

Olick, J.K. \& J. Robbins, 1998. Social memory studies: from 'collective memory' to the historical sociology of mnemonic practices. Annual Review of Sociology 24, 105-40.

Papoulias, C., 2003. From the agora to the junkyard: social memory and psychic materialities, in Regimes of Memory, eds. S. Radstone \& K. Hodgkin. London: Routledge, 114-31.

Popular Memory Group, 1982. Popular memory: theory, politics, method, in Making Histories: Studies in HistoryWriting and Politics, eds. R. Johnson, G. McLennan, B. Schwartz \& D. Sutton. London: Hutchinson, 205-52.

Price, J., 2004. The Ocean Villas project: archaeology in the service of European remembrance, in Matters of Conflict: Material Culture, Memory and the First World War, ed. N.J. Saunders. London: Routledge, 179-91.

Radstone, S., 2000. Working with memory: an introduction, in Memory and Methodology, ed. S. Radstone. Oxford: Berg, 1-24.

Radstone, S., 2005. Reconceiving binaries: the limits of memory. History Workshop Journal 59, 134-50.

Rodgers, B.A., W.M. Coble \& H.K.V. Tilburg, 1998. The lost flying boat of Kaneohe Bay: archaeology of the first U.S. casualties of Pearl Harbor. Historical Archaeology 32(4), 8-18.

Rürup, R., 1996. Topography of Terror: Gestapo, SS and Reichssicherheitshauptamt on the 'Prinz-Albrecht-Terrain': a Documentation. Berlin: Verlag Willmuth Arenhövel.

Saitta, D.J., 2007. The Archaeology of Collective Action. Gainesville (FL): University Press of Florida.

Samuel, R., 1994. Theatres of Memory. London: Verso.

Saunders, N.J., 2004. Material culture and conflict: the Great War, 1914-2003, in Matters of Conflict: Material Culture, Memory and the First World War, ed. N.J. Saunders. London: Routledge, 5-25.

Schofield, J., 2005. Combat Archaeology: Material Culture and Modern Conflict. London: Duckworth.

Schofield, J. \& W. Cocroft (eds.), 2007. A Fearsome Heritage: Diverse Legacies of the Cold War. Walnut Creek (CA): Left Coast Press.

Schofield, J., C.J. Webster \& M.J. Anderton, 2001. Second World War remains on Black Down: a reinterpretation.
Somerset Archaeology and Natural History 1998, 271-86. Schulze, R., 2004. Review article: memory in German history: fragmented noises of meaningful voices of the past? Journal of Contemporary History 39(4), 637-48.

Spitzer, A.B., 1996. Historical Truth and Lies About the Past: Reflections on Dewey, Dreyfus, De Man and Reagan. Chapel Hill (NC): University of North Carolina Press.

Sulieman, S.R., 2006. Crises of Memory and the Second World War. New York (NY): Harvard University Press.

Tarlow, S., 1999. Bereavement and Commemoration: an Archaeology of Mortality. Oxford: Blackwell.

Till, K.E., 2005. The New Berlin: Memory, Politics, Place. Minneapolis (MN): University of Minnesota Press.

Tilley, C., 1989. Excavation as theatre. Antiquity 63, 275-80.

Wallace, J., 2004. Digging the Dirt: the Archaeological Imagination. London: Duckworth.

Wildt, M., U. Jureit \& B. Otte, 2004. Crimes of the German Wehrmacht: Dimensions of a War of Annihilation 1941-1944. An Outline of the Exhibition. Hamburg: Hamburger Edition.

Winter, J., 2000. The generation of memory: reflections on the 'memory boom' in contemporary historical studies. Bulletin of the German Historical Institute 27, 69-92.

Winter, J., 2006. Remembering War: the Great War between Memory and History in the Twentieth Century. New York (NY): Yale University Press.

Winter, J. \& E. Sivan, 1999. Setting the framework, in War and Remembrance in the Twentieth Century, eds. J. Winter \& E. Sivan. Cambridge: Cambridge University Press, 6-39.

Wood, N., 1999. Vectors of Memory: Legacies of Trauma in PostWar Europe. Oxford: Berg.

Yarrow, T., 2006. Sites of knowledge: different ways of knowing an archaeological excavation, in Ethnographies of Archaeological Practice: Cultural Encounters, Material Transformations, ed. M. Edgeworth. Lanham (MD): Altamira, 20-32.

Young, J.E., 1992. The counter-monument: memory against itself in Germany today. Critical Inquiry 18, 267-96.

Young, J.E., 1999. Memory and counter-memory: the end of the monument in Germany. Harvard Design Magazine 9, 1-10.

\section{Author biography}

Gabriel Moshenska recently completed a $\mathrm{PhD}$ on the archaeology, material culture and memory of the Second World War. His research interests include community archaeology, alternative archaeologies, oral history and the material culture of childhood. He is currently a Leverhulme Trust Research Fellow at UCL Institute of Archaeology studying the history of public archaeology. 